\title{
The Fate of Cognition in Very Old Age: Six-Year Longitudinal Findings in the Berlin Aging Study (BASE)
}

\author{
Tania Singer \\ Max Planck Institute for Human Development
}

\author{
Paul Verhaeghen \\ Syracuse University
}

\author{
Paolo Ghisletta, Ulman Lindenberger, and Paul B. Baltes \\ Max Planck Institute for Human Development
}

\begin{abstract}
The authors report full-information longitudinal age gradients in 4 intellectual abilities on the basis of 6-year longitudinal changes in 132 individuals (mean age at $T_{1}=78.27$, age range $=70-100$ ) from the Berlin Aging Study. Relative to the cross-sectional parent sample $\left(N=516\right.$, mean age at $\mathrm{T}_{1}=84.92$ years), this sample was positively selected because of differential mortality and experimental attrition. Perceptual speed, memory, and fluency declined with age. In contrast, knowledge remained stable up to age 90 , with evidence for decline thereafter. Age gradients were more negative in old old $(n=66$, mean age at $\left.T_{1}=83.04\right)$ than in old $\left(n=66\right.$, mean age at $\left.T_{1}=73.77\right)$ participants. Rates of decline did not differ reliably between men and women or between participants with high versus low life-history status. They conclude that intellectual development after age 70 varies by distance to death, age, and intellectual ability domain.
\end{abstract}

On the basis of 6-year longitudinal data from the Berlin Aging Study (BASE), the present article investigates the fate of intellectual abilities in old and very old age. Specifically, its goal is to examine six themes in cognitive aging research: (a) the magnitude of mortality-associated and experimental selectivity effects and their relation to age, (b) the degree of convergence between crosssectional and longitudinal age gradients, (c) the ability-specific differences in the magnitude of age-based changes in the longitudinal sample, (d) the acceleration of decline in old-old age, (e) the relation of gender and life-history variables to level and longitudinal change in intellectual functioning, and (f) the differential association of the fluid mechanics and crystallized pragmatics of

Tania Singer, Paolo Ghisletta, Ulman Lindenberger, and Paul B. Baltes, Max Planck Institute for Human Development, Berlin, Germany; Paul Verhaeghen, Department of Psychology and Center for Health and Behavior, Syracuse University.

The present research was conducted in the context of the Berlin Aging Study (BASE), which is cochaired by Paul B. Baltes and Karl Ulrich Mayer. We acknowledge productive discussions with Florian Schmiedek and Jacqui Smith. Paul Verhaeghen's stay at the Max Planck Institute was supported in part by Grant AG-16201 from the National Institute on Aging.

Correspondence concerning this article should be addressed to Tania Singer, who is now at the Wellcome Department of Imaging Neuroscience, 12 Queens Square, WC1N 3BG London, England; Paul B. Baltes, Max Planck Institute for Human Development, Lentzeallee 94, D-14195 Berlin, Germany; Ulman Lindenberger, who is now at Department of Psychology, Saarland University, D-66123 Saarbrücken, Germany; or Paolo Ghisletta, who is now at Centre for Interdisciplinary Gerontology, University of Geneva, CH-1226 Thônex, GE, Switzerland or Institute for Life Course and Life Style Study (PaVie), University of Lausanne, Bâtiment Provence, CH-1015 Lausanne, VD, Switzerland. E-mail: t.singer@fil.ion.ucl.ac.uk, sekbaltes@mpib-berlin.mpg.de, lindenberger@mx.uni-saarland.de, or paolo.ghisletta@cig.unige.ch intelligence with measures of cultural versus biological indicators. In addition to the description of age changes in intellectual functioning in very old age, we also illustrate methodological issues associated with both cross-sectional and longitudinal studies involving old and very old individuals.

The present study is closely related to other in-depth longitudinal investigations of intelligence in old and very old age, such as the Australian Longitudinal Study (Anstey, Luszcz, Giles, \& Andrews, 2001; Anstey, Luszcz, \& Sanchez, 2001), the Seattle Longitudinal Study (Schaie, 1996), the Victoria Longitudinal Study (Hultsch, Hertzog, Dixon, \& Small, 1998), and the Kungsholmen project on a population 75 years and over (Hill, Wahlin, Winblad, \& Bäckman, 1995; for other longitudinal studies with the focus on old age, see also Colsher \& Wallace, 1991; Giambra, Arenberg, Zonderman, Kawas, \& Costa, 1995; Schaie \& Hofer, 2001; Sliwinski \& Buschke, 1999; Zelinski \& Burnight, 1997). At the same time, it differs from most of these earlier investigations by a combination of three features: (a) the effect-sized-based quantification of selection effects, (b) the decomposition of these effects into mortality-associated and study components (experimental attrition), and (c) the statistical comparisons of cross-sectional and full-information longitudinal age gradients using latent growth models (LGM).

\section{Overview}

In the following, we first provide background information about the longitudinal sample, the design of BASE, and central measures. The subsequent Results section is organized along the six themes described in the first paragraph. To facilitate reading, the theoretical motivation for considering each of the six themes is discussed in conjunction with the outcomes of the relevant analyses. 
In terms of analyses and methods, we first assess mortalityassociated and experimental selectivity effects and their relation to age using an effect-size method for the quantification and decomposition of selectivity effects introduced by Lindenberger, Singer, and Baltes (2002). We then explore cross-sectional and longitudinal age gradients across different intellectual abilities and age groups as well as in relation to different covariates. In these analyses, longitudinal/cross-sectional convergence age gradients are estimated with LGM (e.g., Bryk \& Raudenbush, 1987; Lindenberger \& Ghisletta, in press; McArdle, 1986; McArdle \& Epstein, 1987), using the MLWin software package (Rasbash et al., 2000). With LGM, age gradients are estimated on the basis of latent variables, which makes them less influenced by measurement error and change-independent variance than either raw score differences or residualized change scores. Note, however, that the present LGM analyses are limited by three simplifying assumptions (see also Lindenberger \& Ghisletta, in press). First, the collective 30-year age gradients are synthesized from 6-year individual age segments. Second, these gradients are biased toward the young old because this age group has the largest number of survivors in the longitudinal analysis. Third, these gradients may contain variance that is due to birth-cohort effects in addition to variance that is due to aging.

In our latent growth analyses, we used the full-information raw maximum likelihood estimation algorithm for unbalanced data matrices (e.g., Arbuckle, 1996; McArdle, 1994). This method allows the estimation of all model parameters by utilizing all available data, without either imputing or dropping data when incomplete. The basic principle of this algorithm consists of the automatic individual fitting between each participant's vector of raw data (which is by design incomplete) and the overall group estimated covariance matrix. Individual contributions to the overall misfit are calculated by applying the usual fitting function to the individual data vectors and their respective portion of the overall estimated covariance matrix. Because we are interested in cognitive change as a function of chronological age, we describe the cognitive trajectories over chronological age (i.e., ranging from 70 to 104 years) rather than time in study. Hence, data are incomplete by definition, even for participants assessed during all three occasions of measurement, because no participant could have been measured from age 70 to 104 years.

\section{Method}

More details about the variables assessed, the sample tested, and the procedures used can be found in P. B. Baltes and Mayer (1999), P. B. Baltes and Smith (1997), Lindenberger, Mayr, and Kliegl (1993), and Lindenberger and Baltes (1997). Here, we offer a brief overview.

\section{Sample and Measurement Schedule}

At the first measurement occasion $\left(\mathrm{T}_{1}\right)$, the Berlin Aging Study (BASE) consisted of an initial 14-session in-depth assessment of 516 individuals (age range at first assessment $=70-103$, mean age $=84.9$ years, $S D=8.7$ ). The sample, obtained from the city registry, was stratified by age and gender, resulting in 43 men and 43 women in each of six different age brackets $(70-74,75-79,80-84,85-89,90-94$, and $95+$ years). Selectivity analyses indicate that the 516 individuals who were willing and able to participate in the initial 14-session protocol were already positively selected across a broad range of variables (Lindenberger \& Reischies, 1999). With the exception of dementia prevalence in very old age, however, the amount of observable initial selection bias did not exceed $0.5 S D$ units for any of the variables under consideration

The initial assessment $\left(T_{1}\right)$ was conducted between mid-1990 and June 1993. The longitudinal extension of BASE involved four occasions $\left(T_{1}, T_{2}\right.$, $\mathrm{T}_{3}$, and $\mathrm{T}_{4}$ ), each scheduled about 2 years apart. At the second wave of measurement, only parts of the cognitive test battery were collected. Therefore, this article reports on participants tested at three occasions; that is, the first $\left(\mathrm{T}_{1} ; 1990-1993\right)$, the third $\left(\mathrm{T}_{3} ; 1995-1996\right)$, and the fourth $\left(\mathrm{T}_{4}\right.$; 1997-1998) measurement occasion. On average, $\mathrm{T}_{3}$ data were collected 3.99 years $(S D=0.69)$ and $\mathrm{T}_{4}$ data 6.03 years $(S D=0.80)$ after the initial assessment $T_{1}$. The resulting 6-year longitudinal sample consisted of 132 individuals. To investigate age-related effects in selective drop-out and differential age-related changes between the old and the old-old, for some analyses (see Figures 1, 2, and 4) the present longitudinal sample was split into two groups of equal size (old: $n=66$; mean age at $\mathrm{T}_{1}=73.77$ years, $S D=2.12$, age range $=70-77$ years; old-old: $n=66 ;$ mean age $=83.04$ years, $S D=4.79$, age range $=78-100$ years) ${ }^{1}$

Table 1 reports selected characteristics for the total cross-sectional sample $(N=516)$ at $\mathrm{T}_{1}$ and for the longitudinal sample $(N=132)$ at $\mathrm{T}_{1}, \mathrm{~T}_{3}$, and $\mathrm{T}_{4}$. Characteristics include gender, years of education and age, and average level of intellectual functioning of the relevant samples at each occasion of measurement. Figure 1 shows sample attrition (i.e., the percentage of original participants tested at $T_{1}, T_{3}$, and $T_{4}$ ) as a function of the two age groups. The effects of mortality-associated and experimental sample attrition are examined in more detail in the following paragraphs.

\section{Measures}

Cognitive assessment. The longitudinal cognitive test battery consisted of four intellectual abilities, each assessed by a unit-weighted composite of two tests: (a) perceptual speed (measured by Digit Letter and Identical Pictures); (b) episodic memory (measured by Paired Associates and Memory for Text); (c) fluency (measured by Categories and Word Beginnings); and (d) knowledge (measured by Vocabulary and Spot-a-Word). In the original cross-sectional analysis at $\mathrm{T}_{1}$, reported in Lindenberger and Baltes (1997), three of these four abilities were measured by three tests, and another ability_reasoning-was assessed as well. As a result of time constraints on the follow-up assessments, only four abilities with two tests each were assessed at $\mathrm{T}_{3}$ and $\mathrm{T}_{4}$. Unit-weighted linear composites of the two tests were computed for each of the four intellectual abilities. A detailed description of the tests as well as of their psychometric properties can be found elsewhere (Lindenberger \& Baltes, 1994, 1997; Lindenberger et al., 1993). When participants were assessed on only one of the two variables, that variable's score was used to represent the composite. In contrast to earlier reports (e.g., Lindenberger \& Baltes, 1997), no further

\footnotetext{
${ }^{1}$ The determination of cutoff points for dividing the life span into distinct age periods is somewhat arbitrary. Typical examples include distinctions between young old, old, and oldest old (e.g., Neugarten, 1974; Suzman, Willis, \& Manton, 1992), the old and very old (e.g., Bäckman, Small, Wahlin, \& Larsson, 2000), and the third age and the fourth age (e.g., P. B. Baltes, 1997; P. B. Baltes \& Mayer, 1999; Laslett, 1991). Because of the continuous increase in the general life expectancy of industrialized countries (Manton \& Vaupel, 1995; Vaupel et al., 1998), precise transition ages are difficult to define. One example for a dynamic approach is to speak of the onset of the fourth age as the (historically and contextually conditioned) age at which $50 \%$ of a birth cohort have died (for more detailed discussion, see P. B. Baltes, 2001). In the present analyses, we contrasted individuals in their 70s with individuals in their $80 \mathrm{~s}, 90 \mathrm{~s}$, and older because this split seemed roughly consistent with theoretical considerations and available evidence, with the additional benefit of obtaining two subsamples of equal size.
} 
Table 1

Selected Sample Characteristics, Means and Standard Deviations of Cognitive Abilities, and Ability Correlations With Age, Sensory and Life-History Variables for the Total Cross-Sectional Sample and for the Longitudinal Sample at $T_{1}, T_{3}$, and $T_{4}$

\begin{tabular}{|c|c|c|c|c|c|c|c|}
\hline \multirow[b]{2}{*}{ Characteristic } & \multirow[b]{2}{*}{$n$} & \multirow[b]{2}{*}{$M$} & \multirow[b]{2}{*}{$S D$} & \multicolumn{4}{|c|}{ First-order $r$} \\
\hline & & & & Age & Vision & Hearing & LHS \\
\hline \multicolumn{8}{|c|}{ Total cross-sectional sample at $\mathrm{T}_{1}(N=516)$} \\
\hline Women (\%) & 50 & & & & & & \\
\hline$n$ & 516 & & & & 516 & 515 & 516 \\
\hline Education & 516 & 10.75 & 2.34 & & & & \\
\hline Age & 516 & 84.92 & 8.66 & & -.58 & -.55 & -.08 \\
\hline Intelligence & 514 & 50.00 & 10.00 & -.52 & .53 & .46 & .44 \\
\hline Speed & 440 & 50.00 & 10.00 & -.56 & .57 & .47 & .33 \\
\hline Memory & 510 & 50.00 & 10.00 & -.43 & .36 & .37 & .28 \\
\hline Fluency & 514 & 50.00 & 10.00 & -.45 & .47 & .40 & .37 \\
\hline Knowledge & 447 & 50.00 & 10.00 & -.29 & .39 & .33 & .51 \\
\hline
\end{tabular}

Longitudinal sample at $\mathrm{T}_{1}(n=132)$

\begin{tabular}{|c|c|c|c|c|c|c|c|}
\hline Women $(\%)$ & 55 & & & & & & \\
\hline$n$ & 132 & & & & 132 & 132 & 132 \\
\hline Education & 132 & 11.27 & 2.37 & & & & \\
\hline Age & 132 & 78.27 & 5.92 & & -.36 & -.39 & .06 \\
\hline Intelligence & 132 & 57.34 & 7.81 & -.23 & .29 & .43 & .33 \\
\hline Speed & 124 & 56.96 & 7.29 & -.29 & .36 & .45 & .24 \\
\hline Memory & 132 & 55.61 & 9.74 & -.22 & .12 & .33 & .12 \\
\hline Fluency & 132 & 57.17 & 9.01 & -.16 & .20 & .34 & .25 \\
\hline Knowledge & 125 & 54.29 & 8.22 & .00 & .20 & .23 & .50 \\
\hline
\end{tabular}

\begin{tabular}{|c|c|c|c|c|c|c|c|}
\hline \multicolumn{8}{|c|}{ Longitudinal sample at $\mathrm{T}_{3}(n=132)$} \\
\hline$n$ & 132 & & & & 132 & 129 & 132 \\
\hline Age & 132 & 81.99 & 6.01 & & -.43 & -.43 & .06 \\
\hline Intelligence & 128 & 55.83 & 8.86 & -.28 & .28 & .36 & .24 \\
\hline Speed & 115 & 55.84 & 8.39 & -.41 & .45 & .43 & .11 \\
\hline Memory & 122 & 53.58 & 9.76 & -.21 & .14 & .21 & .16 \\
\hline Fluency & 128 & 55.59 & 9.74 & -.24 & .18 & .29 & .13 \\
\hline Knowledge & 116 & 53.49 & 7.51 & -.12 & .21 & .17 & .46 \\
\hline \multicolumn{8}{|c|}{ Longitudinal sample at $\mathrm{T}_{4}(n=132)$} \\
\hline$n$ & 132 & & & & 132 & 132 & 132 \\
\hline Age & 132 & 83.78 & 5.94 & & -.39 & -.40 & .06 \\
\hline Intelligence & 132 & 55.09 & 9.46 & -.36 & .51 & .51 & .28 \\
\hline Speed & 120 & 54.53 & 9.39 & -.39 & .54 & .44 & .28 \\
\hline Memory & 124 & 53.97 & 9.68 & -.24 & .25 & .29 & .22 \\
\hline Fluency & 126 & 55.49 & 10.21 & -.26 & .23 & .44 & .26 \\
\hline Knowledge & 128 & 54.36 & 8.49 & -.22 & .42 & .38 & .37 \\
\hline
\end{tabular}

Note. All correlations are significant at $p<.05$, except correlations marked in italics. LHS $=$ Lifehistory status, a composite including income, social class, education, and prestige-all assessed at $\mathrm{T}_{1} ; \mathrm{T}=$ Time.

data imputation was applied. A unit-weighted intelligence composite was computed from the four cognitive composites. All five composites were scaled by a linear transformation such that scores at the first measurement occasion for the total sample conform to a $T$ metric (i.e., a mean of 50 and a standard deviation of 10 ).

Sensory functioning. Two types of sensory functioning were assessed: visual and auditory acuity (i.e., vision and hearing). Auditory acuity was measured separately for the right and left ears by using a Bosch ST-201 pure-tone audiometer with headphones. An inverted average score of thresholds in $\mathrm{dB}$ across both ears and four frequencies $(1.00,2.00,4.00$, and $6.00 \mathrm{kHz})$ was used as an estimate of hearing acuity. Visual acuity was measured with and without the best optical correction provided by the participant (i.e., corrective glasses); the best value of the two was used for the analysis. Missing values in individual threshold assessments were replaced by the corresponding value of the other test assessing the construct (see Lindenberger \& Baltes, 1997). The two composites were scaled to conform to a $T$ metric for the total sample at first occasion; a unitweighted sensory composite was constructed based on the vision and hearing composites.

Life-history variables. Four variables were used to represent lifehistory sociocultural status: (a) income (on a 5-point scale), (b) occupational prestige (based on a standard rating scale in Germany), (c) social class (on a 5-point scale), and (d) number of years of education. From these four variables, we constructed a unit-weighted life-history composite. 


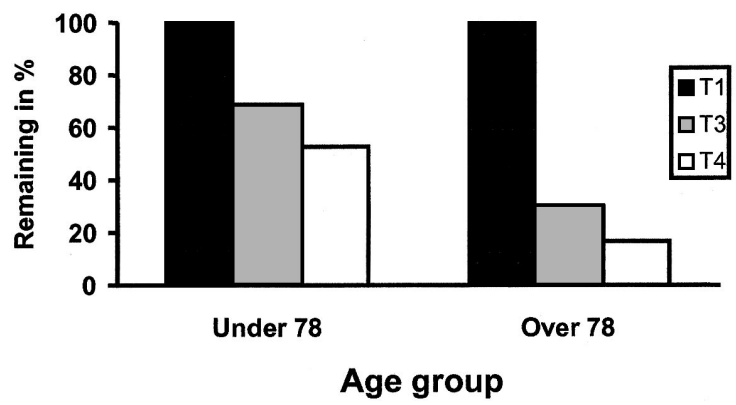

Figure 1. Sample attrition as a function of age group: percentage of original participants tested at $\mathrm{T}_{1}, \mathrm{~T}_{3}$, and $\mathrm{T}_{4} . \mathrm{T}=$ time.

\section{Results}

\section{Decomposition of Longitudinal Selectivity Into Mortality- Associated and Experimental Components}

In addition to the direct assessment of intraindividual change, longitudinal studies allow insights into questions of age-related mortality and experimental attrition effects, with important consequences for the interpretation of cross-sectional age comparisons (for an earlier treatment of these issues, see P. B. Baltes, Reese, \& Nesselroade, 1977). Theoretically, sample attrition could be a random process (i.e., unrelated to the attribute under study), but empirical evidence suggests that sample attrition is generally selective (e.g., P. B. Baltes, Schaie, \& Nardi, 1971; Lindenberger et al., 2002; McArdle, Hamagami, Elias, \& Robbins, 1991; Schaie, Labouvie, \& Barrett, 1973; Siegler \& Botwinick, 1979).

Our first goal was to determine the magnitude of selectivity effects in the 6-year longitudinal sample of BASE. In line with the method described in Lindenberger et al. (2002), we decomposed total selectivity into two components: one mortality-associated (selectivity that was due to differences between individuals who died and individuals who survived) and one experimental (selectivity that was due to differences between surviving individuals who were willing and able to participate in the study and those who were still alive but unwilling or unable to do so). Mortalityassociated selectivity does not compromise the validity of longitudinal observations because dying reflects a population rather than a sample process. In contrast, experimental selectivity introduces a bias and, hence, may limit the generalizability of longitudinal observations because the observed sample is no longer a random subsample of the surviving population.

In addition to the decomposition of total selectivity into mortality-associated and experimental components, we were also interested in determining the magnitude of the relation of both selectivity effects to age. We expected both selectivity effects to increase with age. Figure 1 indicates that sample attrition increased with advancing age. In the older age group $\left(78+\right.$ at $\left.\mathrm{T}_{1}\right)$, less than $20 \%$ of the original sample was available for testing at the last measurement point, as compared with more than $50 \%$ of the younger age group.

Finally, we also examined whether selectivity effects were present with respect to initial level of functioning, subsequent change, or both. In line with previous reports, we expected that participants of the longitudinal sample would start out at higher initial levels and show less negative change over time than partic- ipants who dropped out (e.g., Colsher \& Wallace, 1991; Siegler \& Botwinick, 1979; but see Sliwinski \& Buschke, 1999; cf. Riegel \& Riegel, 1972). Moreover, it is reasonable to assume that individuals who dropped out because they died evinced steeper declines than the surviving nonparticipants and study participants because of "terminal decline" (Riegel \& Riegel, 1972).

Selectivity effects on initial level. We computed the magnitude of longitudinal sample selectivity for the intelligence composite as well as for sensory functioning and sociobiographical status (variables to be used in later analyses as correlates of intelligence). More specifically, mortality-associated and experimental selectivity components were computed by comparing the $\mathrm{T}_{1}$ data of the longitudinal sample $(n=132)$ with those of individuals still alive at the fourth measurement occasion $(n=239)$, and by comparing the data from these survivors with those of the cross-sectional parent sample ( $N=516$; for details on the methods of computing selectivity effects, see Lindenberger et al., 2002). Selectivity effect sizes represent the difference in $T_{1}$ test scores between these three groups expressed as a mean standardized difference, standardized on the standard deviation units of the parent sample:

$$
\begin{gathered}
\text { total selectivity }=\left(M_{\text {select }}-M_{\text {parent }}\right) / S D_{\text {parent sample }} ; \\
\text { experimental selectivity }=\left(M_{\text {select }}-M_{\text {survivors }}\right) / S D_{\text {parent sample }}
\end{gathered}
$$

mortality-associated selectivity

$$
=\left(M_{\text {survivors }}-M_{\text {parent sample }}\right) / S D_{\text {parent sample }} .
$$

To check for age differences in selectivity, this analysis was repeated separately for two age groups; namely, the participants over and under the age of 78 (see above). In these analyses, mean differences were standardized on the standard deviation of the parent sample of the respective age group. Note that the selectivity effects in both age groups do not add up to total selectivity because variability between age groups is not accounted for in the agecomparative selectivity analyses. Figure 2 displays the observed
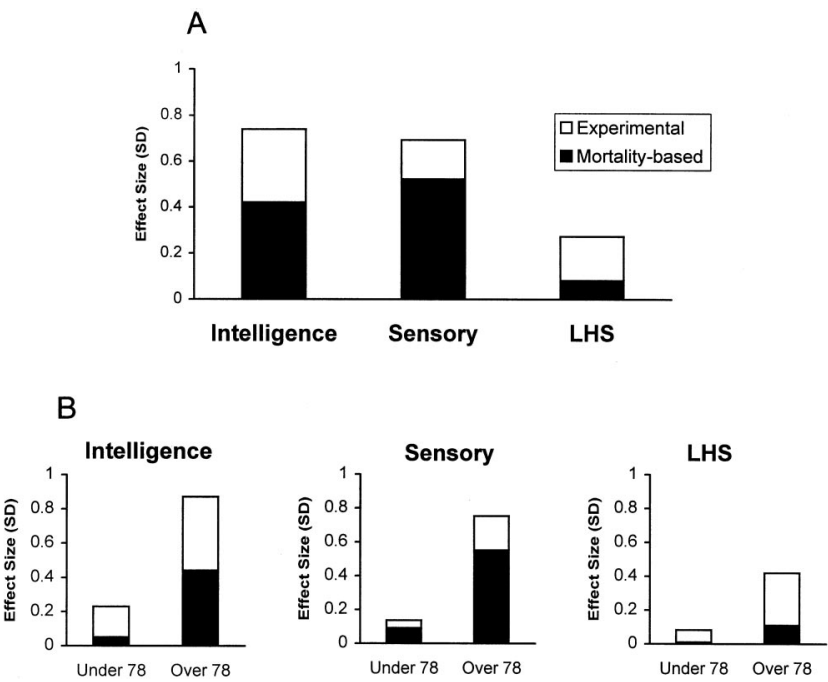

Figure 2. Mortality-associated and experimental selectivity effects for intelligence, sensory functioning, and life-history status (LHS) for the total sample (A), and as a function of age (B). 
selectivity effects for the total sample (top panel) and for the two age groups separately (bottom panel).

Positive selection effects were found for all three sets of variables. The magnitude of total selectivity for the entire sample was $0.74 S D$ units for intelligence, $0.69 S D$ units for sensory functioning, and 0.27 SD units for life-history status (LHS). According to convention (e.g., Cohen, 1977), observed selectivity corresponds to a small effect for life-history differences and to medium effects for intellectual and sensory functioning. Of the total amount of observed selectivity in intelligence, $56 \%$ was due to mortality. For sensory functioning, the relative amount of mortality-associated selectivity was even higher: $75 \%$. For LHS, only $30 \%$ of the total selectivity was due to mortality.

Figure 2 also illustrates that mortality-associated selectivity was not equally distributed over age groups; as predicted, it was larger in the older group (mean magnitude of mortality-associated selectivity $=0.36 S D$ ) than in the younger age group (mean magnitude of mortality associated selectivity $=0.05 S D$ ). Moreover, age effects were also present with respect to the experimental selectivity component: Effect sizes ranged from 0.04 to $0.17 S D$ units in the old age groups and from 0.20 to $0.43 S D$ units in the old-old age group. According to convention (e.g., Cohen, 1977), the observed effect sizes in the old age group are negligible, whereas effect sizes in the old-old age groups correspond to small effects. Note, that although the effect sizes in the oldest age group are nominally larger, the significance of the age differences cannot be tested because the effect size is a descriptive measure derived directly at the group level, and, therefore, no individual variance is associated with it. Nevertheless, the data permit the conclusion, that, in addition to an age-based increase in mortality-associated selectivity, we also observed a nonnegligible degree of mean level bias in the old-old segment of the longitudinal sample because survivors who did not participate in both longitudinal follow-ups had a lower average level of functioning at $T_{1}$ than survivors who participated in both follow-ups.

Selectivity effects on longitudinal change. As a formal test for selectivity effects in change over time, we compared the $\mathrm{T}_{1}$-to- $\mathrm{T}_{3}$ difference scores in perceptual speed, memory, fluency, knowledge, vision, and hearing for individuals who had died between $\mathrm{T}_{3}$ and $\mathrm{T}_{4}(n=39)$ with those who were still alive at $\mathrm{T}_{4}$ but who did not participate $(n=35)$ and with those who did participate at $\mathrm{T}_{4}$ $(n=132)$

The attrition group showed a significant effect for perceptual speed, $F(2,165)=6.11, M S E=38.69$, and for knowledge, $F(2$, $167)=6.12, M S E=28.05$. Post hoc contrasts revealed that these differences were due to the fact that individuals who survived and participated in the study showed lower average rates of decline in perceptual speed and knowledge than those who died after $\mathrm{T}_{3}$. There were no significant differences in the amount of $\mathrm{T}_{1}-\mathrm{T}_{3}$ change between participating and nonparticipating survivors (mean $\mathrm{T}_{1}-\mathrm{T}_{3}$ declines in speed for study participants, surviving nonparticipants, and dead participants were $-1.30,-1.90$, and -5.71 , respectively; mean $\mathrm{T}_{1}-\mathrm{T}_{3}$ declines in knowledge for study participants, surviving nonparticipants, and dead participants were $-1.09,-2.54$, and -4.80 , respectively). Thus, the mortalityassociated component of the selective attrition process, rather than the experimental component, was associated with differential longitudinal losses in intelligence.

In summary, the present longitudinal sample was highly selected in two ways. First, individuals with higher levels of cognitive and sensory functioning and with smaller decline in cognitive functioning (in perceptual speed and knowledge) were more likely to survive. Mortality-associated selectivity was largest for intellectual and sensory variables and close to nonexistent for LHS. This finding is in agreement with the general life span theory (P. B. Baltes, 1997; P. B. Baltes, Staudinger, \& Lindenberger, 1999), which posits that very old age is increasingly determined by biological factors, and less by cultural factors. Second, among the survivors, those with higher initial levels were more likely to continue to participate. This experimental component of selectivity effects was substantial for intelligence but relatively small for sensory and LHS. Specifically, intellectual ability scores in the longitudinal sample at $\mathrm{T}_{1}$ were about three quarters of a standard deviation above those of the total cross-sectional sample. Of this total selectivity effect in intelligence, $57 \%$ was associated with mortality, and $43 \%$ was due to experimental attrition. In contrast, in sensory functioning only, $25 \%$ of the total selectivity was associated with experimental attrition, suggesting that the longitudinal sample was less biased with respect to sensory functioning than with respect to intelligence.

Both experimental and mortality-associated selectivity effects on initial level increased with age, which results in two consequences. First, to the degree that selection effects are associated with age, correlations among variables will be attenuated. Second, our samples of old-old and oldest-old individuals were drawn from populations that differ systematically in composition from the population at younger age segments. In comparison to other largescale studies, chances of observing age-associated selection processes are especially high in BASE because the sample was stratified by age and gender at first occasion (for details, see Lindenberger et al., 1999). Compared with a sampling scheme that mimics the age and gender distribution above a certain age, stratification by age and gender results in a larger proportion of participants in close proximity to death.

\section{Longitudinal Change Versus Cross-Sectional Differences in Intellectual Abilities}

The question about the magnitude of positive age-associated selection effects is closely tied to the question of the influence of such selectivity effects on observed cross-sectional and longitudinal age gradients. Empirical evidence suggests that age gradients obtained from cross-sectional and longitudinal samples diverge (e.g., Schaie, 1996; Sliwinski \& Buschke, 1999; Zelinski \& Burnight, 1997), with some studies suggesting steeper longitudinal than cross-sectional age changes (e.g., Sliwinski \& Buschke, 1999; for some measures, see also Zelinski \& Burnight, 1997), and other studies providing evidence for the reverse pattern, at least for part of the variables (e.g., Schaie, 1996).

There are several reasons why cross-sectional and longitudinal gradients may differ. In addition to the two selection effects discussed, cohort and retest effects may play a role (P. B. Baltes et al., 1977; Schaie, 1965). Such sources may operate simultaneously and in opposing directions, and their specific constellation may not generalize beyond a given study. Nevertheless, when longitudinal samples are compared with the cross-sectional samples from which they originate, selectivity effects and retest effects are likely to dominate this discrepancy because cohort effects are less likely to differ substantially between the two samples. With respect to selectivity effects, longitudinal data condition observations during 
a period of time that is defined by the duration of the longitudinal observation (e.g., 6 years in the present case), whereas corresponding cross-sectional observations on the total sample are conditional upon survival and participation at just one point in time. Therefore, we expected that longitudinal/cross-sectional convergence age gradients based on the 6-year longitudinal sample would show significantly less negative relations to age than $T_{1}$ cross-sectional age gradients of the total sample.

To test this prediction, we compared the age gradients (obtained from latent growth models) among three different subsets of the data: (a) the data of the complete longitudinal sample $(N=132$; $\mathrm{T}_{1}, \mathrm{~T}_{3}$, and $\left.\mathrm{T}_{4}\right)$, (b) $\mathrm{T}_{1}$ data of the total sample $\left(N=516\right.$; $\mathrm{T}_{1}$ only), and (c) $\mathrm{T}_{1}$ data of the longitudinal sample $\left(N=132 ; \mathrm{T}_{1}\right.$ only). The first application is a typical full-information LGM, in which crosssectional/longitudinal convergence data are analyzed to infer age changes. The second and third applications are unusual and serve to assess the degree of similarity, or convergence (Bell, 1953, 1954), between longitudinal and cross-sectional information. In other words, we are interested in testing the possible inconsistencies among age gradients obtained from full-information longitudinal data and age gradients obtained from purely cross-sectional data. The analyses concerning the comparison of the crosssectional and longitudinal age gradients involve testing two sets of nested models: one set testing for linear slope differences and one testing simultaneously for differences in linear and quadratic change. More specifically, in a first step, we forced (a) the crosssectional age gradient of the longitudinal sample $(N=132)$ and (b) the cross-sectional age gradient of the total sample $(N=516)$ to be equal to the longitudinal age gradient. In the second step, we relaxed the equality constraint, first for the mean of the linear slope and second for the mean of the quadratic slope. Statistical conclusions about such model comparisons are based on differences in likelihood ratios distributed asymptotically as a chi-square with one degree of freedom representing each gradient tested (i.e., $d f=1$ for linear slope tests, $d f=2$ for linear and quadratic slope tests; see Ghisletta \& McArdle, 2001).

Figure 3 shows the longitudinal age gradients calculated for the longitudinal sample, taking each measurement point into account (thick black line), as well as the cross-sectional age gradient calculated for the total sample at first occasion (short-dashed line) and the cross-sectional age gradient for the longitudinal sample at its first measurement occasion (thin black line).

Note first that for all four intellectual abilities and for the intelligence composite, the longitudinal linear gradients did not differ reliably from the cross-sectional age gradients obtained at $\mathrm{T}_{1}$ from the longitudinal sample, $\chi^{2}(1, N=132)=$ for perceptual speed and fluency, and $\chi^{2}(1, N=132)=0$ for memory, knowledge, and the intelligence composite. When the quadratic gradient was added to the analyses, the only significant discrepancy between longitudinal and $\mathrm{T}_{1}$ cross-sectional results of the longitudinal sample was found for perceptual speed, $\chi^{2}(2, N=132)=11$. The longitudinal age gradient of speed showed more decline than the $\mathrm{T}_{1}$ cross-sectional age gradient: for memory, $\chi^{2}(2, N=$ $132)=0$, for knowledge and fluency, $\chi^{2}(2, N=132)=5$, and for the intelligence composite, $\chi^{2}(2, N=132)=4$.

By contrast, the $T_{1}$ cross-sectional linear gradients as obtained from the total sample were significantly steeper than the longitudinal gradients for all four abilities and for the composite: $\chi^{2}(1$, $N=516)=20$ for perceptual speed, 7 for memory, 41 for knowledge, 15 for fluency, and 25 for the intelligence composite.
Relaxing the equality constraint for the quadratic terms likewise led to significant increases in fit for all four abilities and for the composite, indicating steeper quadratic declines in the crosssectional sample, $\chi^{2}(2, N=516)=39$ for perceptual speed, 7 for memory, 52 for knowledge, 24 for fluency, and 35 for the intelligence composite.

In summary, the longitudinal and the first-occasion crosssectional age gradients observed for the longitudinal sample resemble each other closely. In contrast, the age differences observed in the $T_{1}$ cross-sectional sample follow a significantly more negative path. In line with the results of the selectivity analyses reported previously, this finding indicates substantial discrepancy between the total cross-sectional sample and the longitudinal subsample. Relative to the longitudinal sample, the more negative age gradients observed in the cross-sectional parent sample are likely to reflect a greater age-associated increase in the proportion of individuals close to death. Conversely, the $\mathrm{T}_{1}$ cross-sectional gradient of the longitudinal study participants is likely to be less contaminated by the effects of ill health or impending death than the cross-sectional age gradient of the parent sample. Finally, for perceptual speed, the full-information longitudinal age gradient was more negative than the $T_{1}$ cross-sectional age gradient of the same sample. This observation is consistent with previous findings from the Seattle Longitudinal Study, in which analogous differences were observed for perceptual speed and numerical ability (Schaie, 1996). It also is in line with the selectivity effects regarding change reported previously.

In summary, we submit that the cross-sectional age gradients of the total sample were more contaminated with the effects of terminal decline and cognition-related disease processes than the age gradients of the 6-year longitudinal sample. This observation may hold true for comparisons between cross-sectional and longitudinal information on aging populations in general (cf. Sliwinski, Lipton, Buschke, \& Stewart, 1996).

\section{Ability-Specific Differences in the Magnitude of Age-Based Decrements in the Longitudinal Sample}

Previous cross-sectional analyses from BASE revealed that intellectual functioning in old and very old age is somewhat different from earlier portions of the life span (Lindenberger \& Baltes, 1997). For example, over the course of the adult life span, age gradients for fluid-mechanic and for crystallized-pragmatic aspects of cognition tend to diverge. Fluid abilities show relatively large negative age differences, whereas crystallized abilities evince stability or even positive age differences (P. B. Baltes, 1987; P. B. Baltes et al., 1999; Cattell, 1971; Horn, 1982; Schaie, 1996). Cross-sectional findings based on the first-occasion parent sample of BASE suggested that this multidirectional pattern may no longer hold in very old age- - both fluid and crystallized abilities were negatively related to age. This pattern is referred to as directionality dedifferentiation. Here, we examine whether longitudinal change obtained from the same data set follows this general pattern of directionality dedifferentiation observed in crosssectional age comparisons.

In contrast to the cross-sectional data, Figure 3 suggests stability for one dimension, namely, knowledge, in the presence of significant decline in the other three abilities. The observed yearly linear decline, expressed in $T$-score units, was 0.53 for perceptual speed, 0.38 for memory, 0.36 for fluency, -0.02 for knowledge 


\section{Intelligence}

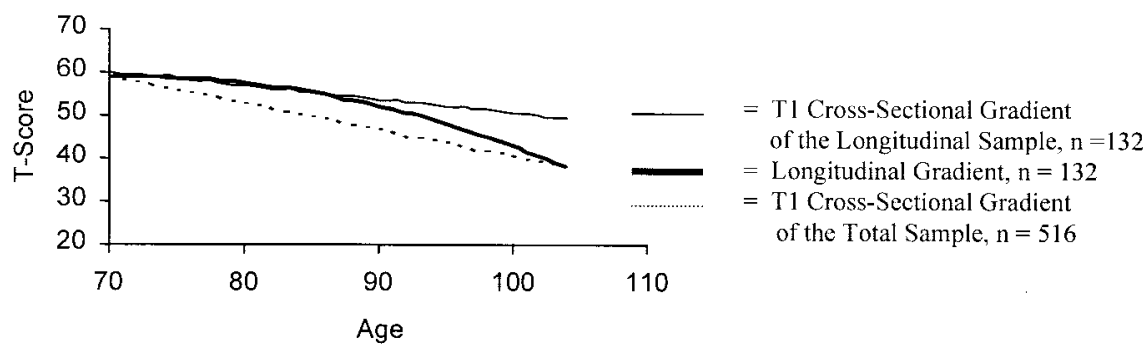

Speed

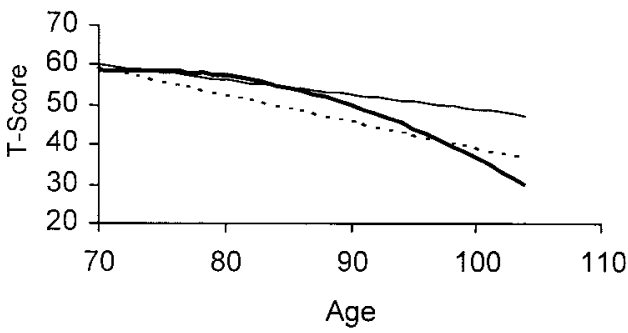

Memory

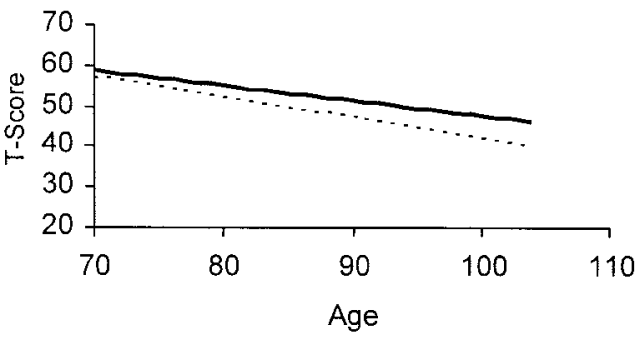

Knowledge

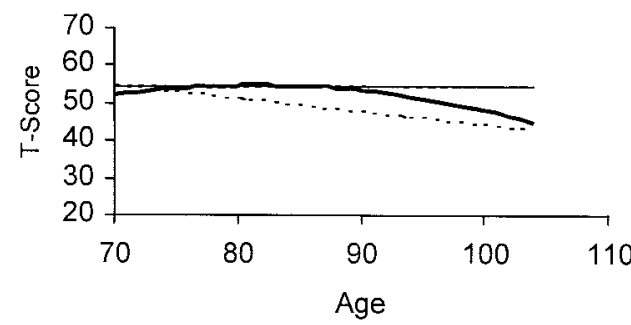

Fluency

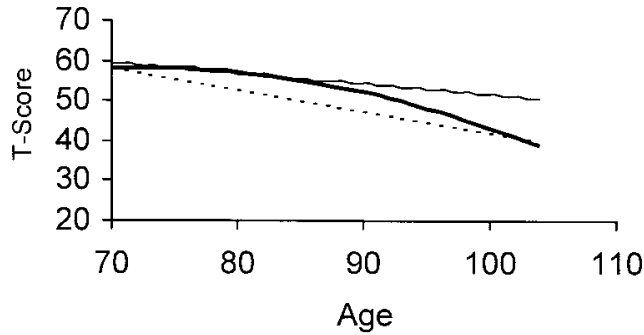

Figure 3. Cognitive functioning over the time course of the Berlin Aging Study. The thick black lines represent the estimated longitudinal change gradients as observed over the 6-year interval in the longitudinal sample $(N=$ 132). The short-dashed lines represent the cross-sectional age gradient as observed in the initial assessment of the total sample $(N=516)$. The thin black lines represent the cross-sectional age gradient as observed in the initial assessment of the longitudinal sample. $\mathrm{T} 1=$ time.

( $p=.265$ ), and 0.40 for intelligence. To test for differential decline across abilities, we examined all possible pairwise combinations of the four abilities, using a nested models approach in which we again concentrated on those LGM parameters analogous to the linear and, when significant, quadratic age trends. The only cognitive ability that differed significantly from any of the other cognitive abilities with respect to estimated longitudinal change was knowledge; that is, $\chi^{2}(2, N=132)=28$ when knowledge was compared with perceptual speed, 17 when compared with memory, and 14 when compared with fluency.
In summary, our longitudinal analyses show that the pattern of directionality dedifferentiation of age gradients observed in the total cross-sectional sample at $\mathrm{T}_{1}(N=516)$ was less pronounced in the longitudinal sample (for similar longitudinal findings, see also Deary, MacLennan, \& Starr, 1998; Schaie, 1996). Whereas perceptual speed, memory, and fluency declined significantly with age, the marker ability of crystallized-pragmatic intelligence knowledge did not decline significantly, although inspection of Figure 3 and additional analyses (see next paragraph) suggest that knowledge may decline after age 90. Apparently, knowledge can 
evince a high degree of late-life stability in positively selected samples of longtime survivors.

With respect to knowledge, and from a general developmental perspective, these findings indicate some preserved continuity in the structural pattern of age changes in cognitive functioning from old to very old age as well as continuity to earlier periods of the life span (Cattell, 1971; Horn, 1982; Schaie, 1996; see also Ghisletta \& Lindenberger, 2003, for limits to continuity). This form of continuity was not observed for fluency, originally conceptualized (Lindenberger \& Baltes, 1994) as a second marker of the broad crystallized domain. With respect to longitudinal change, fluency did not differ significantly from perceptual speed and memory, both of which represent the broad fluid domain. Clearly, performance on fluency tasks draws heavily on semantic knowledge but also requires speeded executive and retrieval processes (Salthouse, 1993). As a consequence, performance on fluency tasks may be more susceptible to decline in the mechanics of cognition than performance on knowledge tasks (cf. Lindenberger \& Baltes, 1997; Mayr \& Kliegl, 2000).

\section{Differences in Age Gradients Between the Old and the old-Old}

Based on an analysis of the overall landscape of the biologicalgenetic and cultural-social architecture of the life course, recent efforts in life span theory have emphasized the specific character of the oldest-old population, or fourth age, suggesting that the causal systems of aging in the oldest old may differ from those of earlier ages (M. M. Baltes, 1998; P. B. Baltes, 1997; P. B. Baltes et al., 1999). Cross-sectional data and cognitive training research suggest that losses in fourth age are (a) more pronounced, (b) broader, (c) less subject to intervention, and (d) increasingly more regulated by biological and less by cultural factors (Lindenberger \& Baltes, 1994, 1997; Singer, Lindenberger, \& Baltes, 2003; Smith \& Baltes, 1999). In addition, findings from several other longitudinal studies provide evidence for nonlinear age trends in samples of old and very old participants (e.g., Colsher \& Wallace, 1991; Giambra et al., 1995; Schaie, 1996). For example, in the Baltimore Longitudinal Study of Aging, declines were found to be more precipitous in the 70s than at earlier adult ages (Giambra et al., 1995). The authors discussed the "watershed" of the seventh decade, arguing that declines increase nonlinearly after age 70 . Similarly, age differences in mental status scores and performance on a memory test have been found to be largest in individuals over the age of 85 , suggesting that very old age is associated with more rapid declines (Colsher \& Wallace, 1991).

As stated previously, the present longitudinal sample was split into two groups of equal size to allow for the investigation of differential age-related changes between old and the old old (old: $n=66$, mean age at $\mathrm{T}_{1}=73.77$ years, $S D=2.12$; age range $=$ $70-77$ years; old old: $n=66$, mean age $=83.04$ years, $\mathrm{SD}=4.79$, age range $=78-100$ years).

In the "younger" old subsample, the linear yearly age change as estimated by LGM was -0.25 for perceptual speed, -0.31 for memory, -0.23 for fluency, 0.12 for knowledge $(p=.216)$, and -0.20 for intelligence. None of the quadratic change components differed significantly from zero. The "older" old subsample showed nominally steeper yearly age changes for all cognitive abilities than the old subsample: -0.81 for perceptual speed, -0.61 for memory, -0.53 for fluency, -0.20 for knowledge, and
-0.63 for intelligence. Moreover, in the old-old sample, the quadratic change components reached significance for two of the abilities: namely, perceptual speed $(-0.05)$ and knowledge $(-0.03)$.

To formally test for subsample differences in change, we forced the parameter estimates of the means of the linear and, when significant, quadratic slopes of the old-old subsample on the equivalent LGM parameters of the old subsample, and then relaxed this constraint. All differences in change between the old and old-old sample were significant, $\chi^{2}(2, N=132)=23$ for perceptual speed, $\chi^{2}(1, N=132)=5$ for memory, $\chi^{2}(1, N=132)=6$ for fluency, $\chi^{2}(2, N=132)=10$ for knowledge, and $\chi^{2}(1, N=$ $132)=18$ for the intelligence composite, revealing larger negative longitudinal change in the old-old sample than in the old sample. Figure 4 displays the longitudinal age gradients in intelligence and in the four intellectual abilities separately for the old (black line) and the old-old (short-dashed line) subsamples.

Inspection of the data suggests that the observed quadratic trends were probably due to a precipitous decline among the oldest participants of the old-old sample. To examine this possibility, we repeated the LGM analyses of the old-old subsample after excluding the small $(n=6)$ group of individuals aged 90 or older at $\mathrm{T}_{1}$ ( $n=60$; note that the criterion of a minimum of five observations per estimated parameter continued to be met). Results were analogous to those obtained with the entire subsample of the 66 old-old participants, with the notable exception of knowledge, in which the quadratic component of change was no longer significantly different from zero. With respect to the longitudinal sample, this finding reinforces the impression that the emergence of a negative age gradient in knowledge was primarily brought about by the oldest individuals in the sample. Given the very advanced age of these participants, this decline may have been primarily due to terminal drop (e.g., Berg, 1996), and not to normal aging. Note, however, that these findings are based on only six individuals and should therefore be interpreted with caution.

In summary, on the basis of age-comparative two-group analyses, we conclude that individuals in their 70s showed less marked decline than individuals in their 80 s and 90 s on all four intellectual abilities. With respect to perceptual speed and knowledge, decline continued to accelerate within the old-old age group. These findings gain in significance if we consider the fact that the oldest-old represent an increasingly positive selection of their respective cohorts. Our findings are consistent with previous longitudinal reports showing nonlinear decline in samples of old and very old participants (e.g., Colsher \& Wallace, 1991; Giambra et al., 1995; Schaie, 1996). Furthermore, accelerated decline in the oldest old is consistent with the life span theory emphasizing the special status of the old-old population (M. M. Baltes, 1998; P. B. Baltes, 1997; P. B. Baltes et al., 1999).

Because of the magnitude of intelligence-related selection operating in the present sample, the age at which we observed negatively accelerated decline is probably elevated compared with less selected age-heterogeneous samples that contain more individuals affected by poor health and impending death. Additional analyses focusing on distance to death rather than on chronological age are needed to better disentangle age-linked processes from mortality-linked processes in old and very old ages. The present results suggest, for instance, that intellectual discontinuity is strongly induced by mortality-associated factors, which increasingly define the life conditions of persons in old-old age. 


\section{Intelligence}

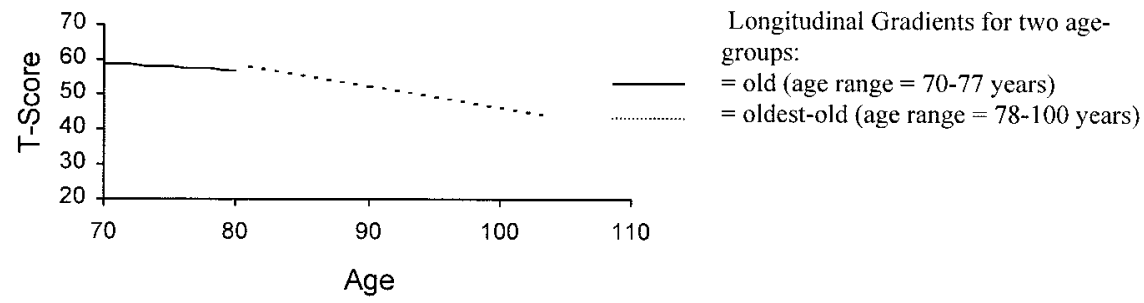

\section{Speed}

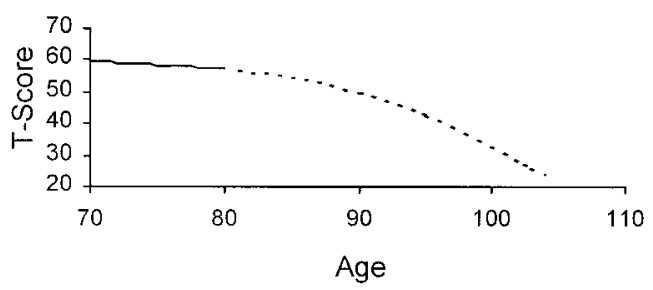

Memory

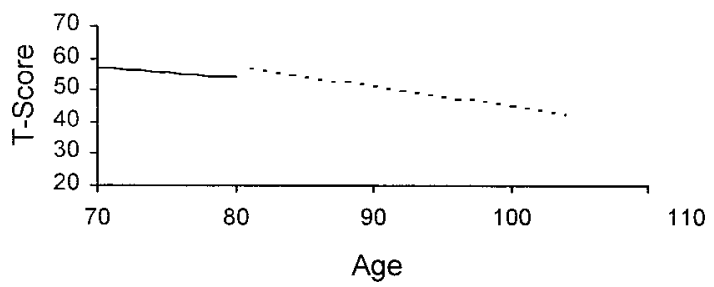

Knowledge

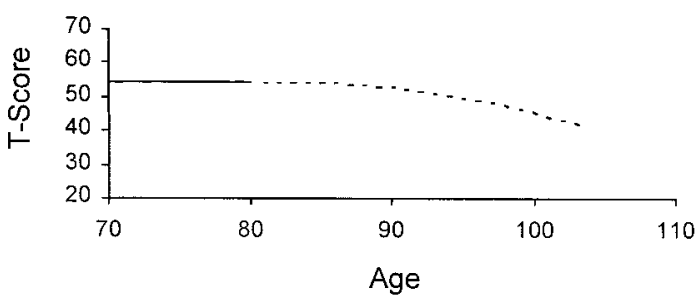

Fluency

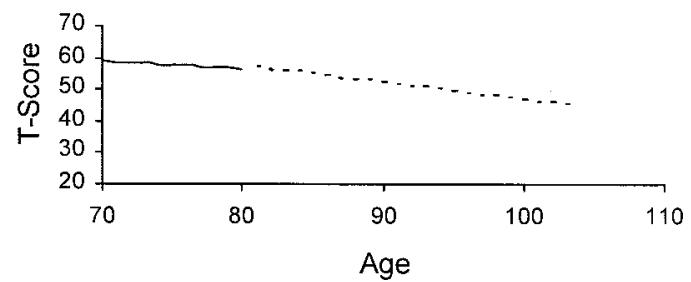

Figure 4. Estimated longitudinal change gradients in cognitive functioning for two different age groups, the old (black lines; $n=66$; mean age at $\mathrm{T}_{1}=73.77$ years; $S D=2.12$; age range $=70-77$ years) and the oldest old (short-dashed lines; $n=66$; mean age $=83.04$ years; $S D=4.79$; age range $=78-100$ years). $\mathrm{T}=$ time.

\section{Covariates of Intellectual Functioning in Very Old Age}

In a last set of analyses, covariates of cognitive functioning were assessed in the longitudinal sample. Here, we focused on three main questions: (a) Do men and women differ with respect to initial level or longitudinal change in intellectual functioning? (b) Do we find longitudinal evidence for the assumption that age is kinder to the initially more able? and (c) Are crystallizedpragmatic and fluid-mechanic intellectual abilities differentially related to sociocultural and biological systems of influence?

The effect of gender and life-history differences on cognitive decline. A female superiority on episodic memory performance has been found in several large-scale studies across the entire adult age range including old age (e.g., Herlitz, Nilsson, \& Bäckman, 1997; Inouye, Albert, Mohs, Sun, \& Berkman, 1993; Schaie, 1996;
Zelinski, Gilewski, \& Schaie, 1993). Accordingly, cross-sectional findings in BASE (Lindenberger \& Baltes, 1997) showed that previous advantages in level of cognitive functioning for men in reasoning and knowledge disappeared when controlling for individual differences in education, while an advantage in memory for women emerged.

With regard to differences in sociobiographical or LHS (Lindenberger \& Baltes, 1997), cross-sectional findings in BASE showed that even though individuals with high scores on desirable life-history and sociocultural variables entered old age with higher levels of functioning, their negative age gradients were identical to those of individuals with lower sociobiographical status. According to an extensive literature review by Anstey and Christensen (2000), who summarized 34 studies 
with sufficient longitudinal data to permit prediction of individual differences in cognitive change, the effects of education on cognitive change are inconsistent. Some studies reported the rate of decline being less rapid for the more educated, other studies failed to find an effect of education on cognitive change, and still other studies showed that the effect of education on cognitive change was restricted to a subgroup or subgroups (sex or age groups) or to particular types of outcome measures. There is also evidence that education may be protective up to young-old age but not in old-old age (e.g., Butler, Ashford, \& Snowdon, 1996). The studies reviewed differed widely with respect to cognitive measures included, sample size, and age distribution of the samples. With few exceptions, the samples were much younger than the BASE sample. Thus, only limited information is available on longitudinal change in very old age as a function of sociobiographical and life-history factors.

As suggested by the life span theory (P. B. Baltes et al., 1999), in very old age, cognition is assumed to become increasingly dependent on changes in the neurobiological integrity of the brain and less regulated by cultural factors and socioenvironmental conditions. Accordingly, we expected longitudinal age gradients to be similar for individuals scoring high and low on LHS.

Table 1 reports the correlations of the four intellectual abilities with age, the life-history composite (income, social class, education, and prestige), and the sensory variables (vision, hearing) in the total cross-sectional parent sample, as well as in the longitudinal sample at all three measurement occasions $\left(\mathrm{T}_{1}, \mathrm{~T}_{3}\right.$, and $\left.\mathrm{T}_{4}\right)$.

To test for the effects of gender and of life-history variables (i.e., the LHS composite) on level and change of cognitive functioning, these two variables were included as covariates in the LGM on the longitudinal sample $(N=132)$. Both simple and unique effects of gender and LHS were computed. Results of these analyses are reported in Table 2.

Women scored higher than men on memory, fluency, and the intelligence composite (unique effects of gender are 4.63, 2.77, and 3.14 $T$-score units, respectively). Moreover, when differences in life-history variables were taken into account, the gender advantage of women in these cognitive domains increased to $5.09,3.25$, and $3.81 \mathrm{~T}$-score units for memory, fluency, and intelligence, respectively. Despite such differences in level, how-

Table 2

Unique and Simple Effects of Gender and Life History on Levels and Change of Cognitive Abilities

\begin{tabular}{cccccc}
\hline & \multicolumn{5}{c}{ Cognitive ability } \\
\cline { 2 - 6 } Effect & Speed & Memory & Fluency & Knowledge & Intelligence \\
\hline Gender & $2.18(1.71)$ & $5.09(4.63)$ & $3.25(2.77)$ & $1.21(0.33)$ & $3.81(3.14)$ \\
on L & & & & & \\
LHS on L & $0.18(0.18)$ & $0.20(0.17)$ & $0.22(0.20)$ & $0.36(0.36)$ & $0.28(0.26)$ \\
Gender $\times$ & $-0.02(0.18)$ & $0.26(0.31)$ & $0.17(0.29)$ & $0.20(0.47)$ & $0.20(0.37)$ \\
LHS & & & & & \\
on L & & & & & \\
\hline
\end{tabular}

Note. Unique effects are in parentheses. Values marked in italics are not significant. The covariates did not significantly predict change. In all analyses, life-history differences (LHS) was entered as a variable as $T$ score units at $\mathrm{T}_{1}(M=50, S D=10) . \mathrm{L}=$ level; $\mathrm{LHS}=$ life-history status; $\mathrm{T}=$ time. ever, the null hypothesis of equivalent cognitive longitudinal change in men and women could not be rejected for any of the four abilities or for the intelligence composite.

Higher levels in desirable life-history and sociocultural status were associated with higher level of functioning on all four cognitive abilities and on the intelligence composite (effects ranged from 1.8 to $3.6 T$-score differences in cognitive performance for each standard deviation difference in LHS). Level of LHS, however, did not predict differential change in any of the cognitive abilities.

To illustrate the findings regarding gender and life-history variables, Figure 5 shows the longitudinal gradients for cognitive functioning (perceptual speed, memory, fluency, and knowledge), split by gender (A) and LHS groups (B). The two LHS groups illustrated in Figure 5 represent individuals who scored $1 S D$ above, respectively below, the mean of the LHS composite. Groups differ in level, but estimated longitudinal age trajectories remain parallel.

In summary, our longitudinal analyses suggest that decline in cognitive functioning is uniform across different groupings of individuals typically included in macrostructural work such as by gender or social stratification. These group-equivalent longitudinal decline patterns replicate cross-sectional findings at $\mathrm{T}_{1}$ (Lindenberger \& Baltes, 1997) and are consistent with earlier longitudinal findings (e.g., Carmelli, Swan, LaRue, \& Eslinger, 1997; Gribbin, Schaie, \& Parham, 1989; Hultsch et al., 1998; Schaie, 1996; Siegler, 1983; but see Albert et al., 1995; Deary et al., 1998; Kohn \& Schooler, 1978, 1983).

The lack of differential longitudinal age changes notwithstanding, note that group differences were present with respect to levels of intellectual functioning. First, in agreement with earlier reports (e.g., Herlitz et al., 1997; Inouye et al., 1993; Schaie, 1996; Zelinski et al., 1993), women surviving into very old age scored higher than men on memory and fluency. Notably, these advantages of women were even more pronounced when gender differences in educational level were statistically taken into account. Second, life-history variables such as income, social class, and education were found to be positively associated with higher levels of functioning on all four intellectual abilities. Such differences in level of intellectual functioning by gender and socioeconomic LHS can have significant consequences for everyday competence with severe real-life implications. Higher cognitive resources, for instance, permit better everyday functioning in old age (M. M. Baltes \& Lang, 1997) and protect individuals for a longer time from falling below critical levels or "thresholds" of dysfunctionality. It follows that women and individuals with higher LHS are likely to pass the dysfunctionality threshold later in life than men and individuals with lower LHS (cf. Lindenberger \& Reischies, 1999, p. 342).

Testing explanatory life span theory of intelligence: Abilityspecific relations to (cultural) life-history and (biological) sensory variables. Many theoretical conceptions about the life span fate of cognitive functioning posit the influence of two distinct but interrelated systems of influence on intellectual development: the biological and the cultural (e.g., P. B. Baltes, 1997; P. B. Baltes \& Singer, 2001; Cattell, 1971; Horn, 1982; Rybash, Hoyer, \& Roodin, 1986). In line with these conceptions, earlier crosssectional analyses of BASE revealed that individual differences in fluid-mechanic (e.g., perceptual speed) and crystallized-pragmatic 


\section{Longitudinal Change as a Function of}
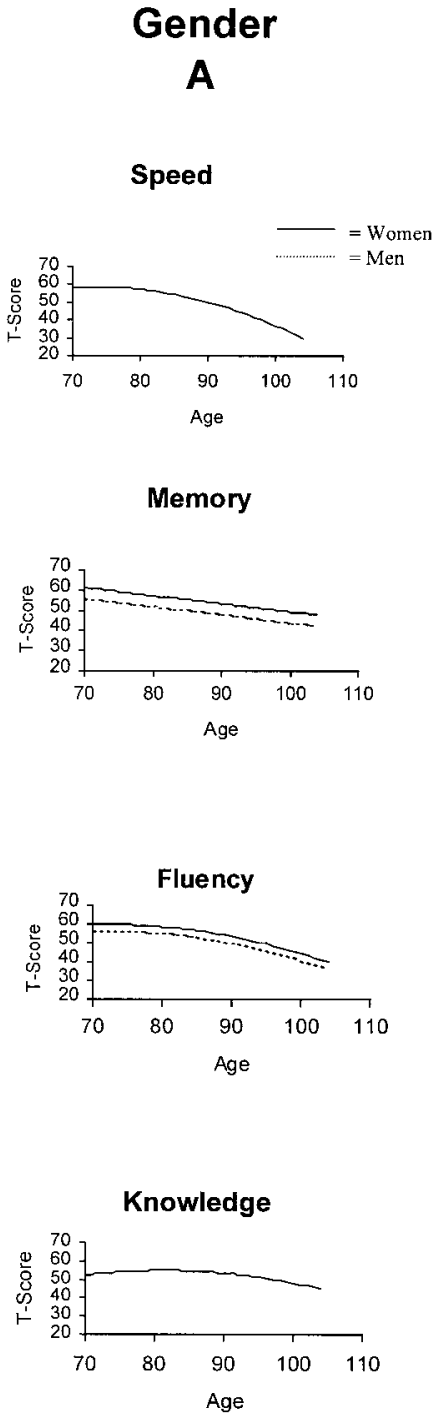

Life-History Differences (LHS)

B

Speed
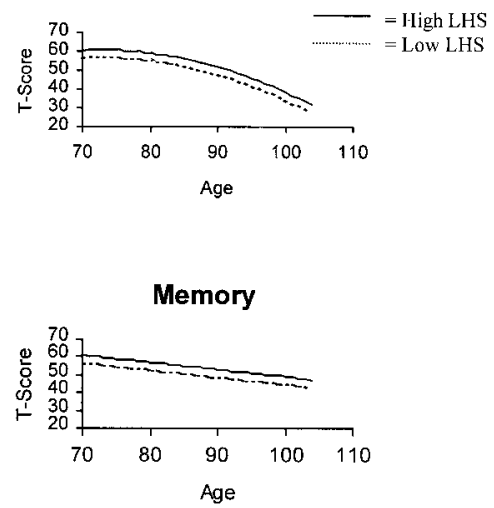

Fluency

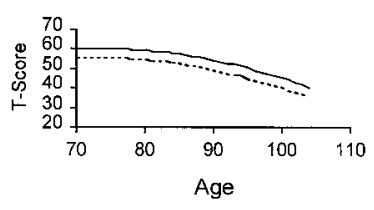

Knowledge

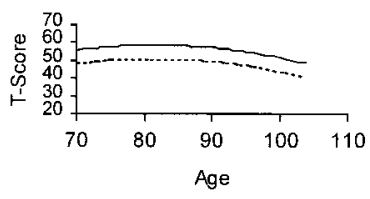

Figure 5. Estimated longitudinal change gradients in cognitive functioning as a function of gender (A) and life-history status (B). A: Gender, black lines represent women, and short-dashed lines men. B: Life-history differences (LHS), black lines represent individuals above $1 S D$ of the mean in the life-history composite, and short-dashed lines represent individuals below $1 S D$ of the mean in the life-history composite. The life-history composite is based on education, income, social class, and prestige.

(e.g., knowledge) aspects were differentially related to individual differences in biological (e.g., sensory variables) and sociobiographical correlates (Lindenberger \& Baltes, 1997). We expected to replicate these findings in the BASE longitudinal sample.

In Figure 6, we report the correlations of perceptual speed and knowledge, each averaged over the three testing occasions, with the two sensory variables, also averaged over the three testing occasions, and with the four life-history sociocultural variables. All correlations are significant, with the exception of the correlations between perceptual speed and social class, between perceptual speed and income, and between knowledge and income. Tests for the differences between correlations involving perceptual speed and those involving knowledge showed significantly larger correlations with perceptual speed than with knowledge for vision $(z=2.27)$ and hearing $(z=1.89$, one-tailed test), and significantly larger correlations with knowledge than with perceptual speed for social class $(z=$ $-2.45)$ and occupational prestige $(z=-1.96)$, as well as statistically nonreliable trends in the same direction for years of education $(z=-1.57)$ and income $(z=-0.68)$. These results confirm the continued divergent validity of the two-component life span theory of intelligence up to very old age (P. B. Baltes et al., 1999; Cattell, 1971; Horn, 1982; Lindenberger, 2001; see Lindenberger \& Baltes, 1997). 


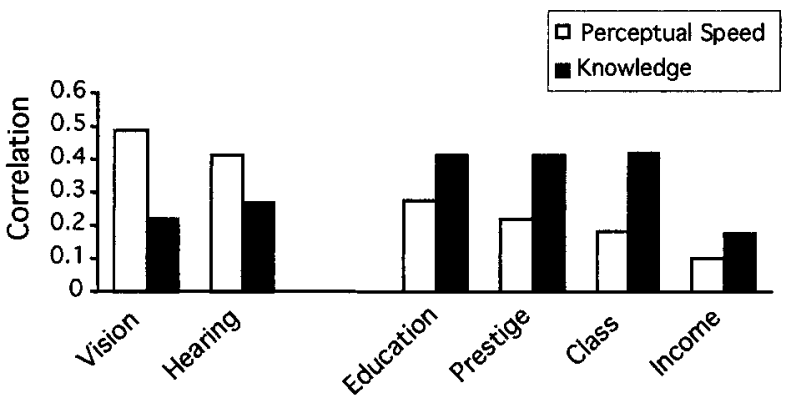

Figure 6. Correlations of four life-history variables and two sensory variables with perceptual speed and knowledge (the variables vision, hearing, perceptual speed, and knowledge were each averaged over the three testing occasions).

\section{Summary of Findings}

In this study, we analyzed 6-year longitudinal data, obtained from 132 old and very old individuals, assessed on a fairly comprehensive set of measures of intellectual functioning. Two closely connected lines of questioning guided our analysis: one methodological and one theoretical. With regard to methodology, our study highlights the conjoint effects of populationbased and sample-based selectivity effects on cross-sectional and longitudinal age gradients in intellectual functioning. With regard to theory, the goal was to relate the findings to the general framework of the life span theory (P. B. Baltes, 1997; P. B. Baltes et al., 1999).

The results can be summarized as follows. First, we observed sizeable mortality-associated and experimental selectivity effects with respect to initial intellectual and sensory levels of performance in the 6-year longitudinal sample. These selectivity effects tended to be larger in the old-old segment than in the old segment of the longitudinal sample. Moreover, the longitudinal (6-year) study participants and surviving nonparticipants evinced less longitudinal decline from $\mathrm{T}_{1}$ to $\mathrm{T}_{3}$ than did participants who died after $\mathrm{T}_{3}$. Second, the cross-sectional age gradients calculated from the total parent sample at $\mathrm{T}_{1}$ were steeper than the longitudinal age gradients, but $\mathrm{T}_{1}$ cross-sectional and $\mathrm{T}_{1}-\mathrm{T}_{4}$ longitudinal age gradients based on the longitudinal sample were nearly identical. Third, in our $\mathrm{T}_{1}-\mathrm{T}_{4}$ longitudinal data, we found evidence for reliable quadratic components of change for all intellectual abilities, with the exception of memory. This stands in contrast to cross-sectional age results obtained for the total sample at $\mathrm{T}_{1}$ (Lindenberger \& Baltes, 1997), which showed only linear trends. Fourth, we found evidence for the existence of two different patterns of trajectories: Perceptual speed, memory, and fluency showed similar amounts of decline, whereas knowledge showed preserved stability until about age 90 . Fifth, negative $T_{1}-T_{4}$ longitudinal changes with respect to all four intellectual abilities were more pronounced in the old old as compared with the old. Sixth, there was evidence for associations of gender and life-history variables with initial level of cognitive functioning but no evidence for differences in the amount of longitudinal decline as a function of gender or LHS. Seventh, in line with earlier cross-sectional findings (Lindenberger \& Baltes, 1997), we found that knowledge was more closely related to sociobiographical markers than to perceptual speed and that perceptual speed was more closely related to biological markers than to knowledge.
Limitations of the Present Study

There are several factors that affect the external and internal validity of the interpretation advanced. Regarding external validity or generalizability, we note that BASE was a very intensive and time-consuming study involving around 27 sessions of measurement for each individual up to the fourth measurement occasion (usually 14 sessions at $\mathrm{T}_{1}, 1$ session at $\mathrm{T}_{2}, 6$ sessions at $\mathrm{T}_{3}$ and $\mathrm{T}_{4}$, respectively). This intensity may have played a role in an individual's decision to participate in the first and in the subsequent waves. Therefore, it may be possible that the magnitude of experimental attrition and the selectivity of attrition with respect to cognitive status were more pronounced in the present study than would be observed in less intensive studies of cognitive aging.

There are also issues of internal validity regarding the interpretation of age changes. As noted before, our analyses neglect the possible role of retest effects in longitudinal data and cohort effects in cross-sectional as well as in longitudinal data. To better estimate the relative role of each of these contributors to the observed effects, we would need a comprehensive cohort-sequential design with repeated and independent observations (e.g., P. B. Baltes et al., 1977; Schaie, 1965; Schaie \& Baltes, 1975). One illustration of how these effects might operate in confluence is the similarity between the longitudinal and $\mathrm{T}_{1}$ cross-sectional gradients of the longitudinal sample. If retest effects were the only factor operating, then we would expect the longitudinal gradients to be shallower than the cross-sectional gradients; this was not the case. If, however, a cohort effect is operating that favors, for instance, the earlier birth cohorts, then this cohort effect might cancel out the observed retest effects.

Commonly, cohort differences are assumed to affect primarily the internal validity of the age comparisons of cross-sectional studies. In contrast, the primary concerns regarding longitudinal age-comparative research are usually more about the question of external validity of the cohort studied; that is, whether longitudinal age gradients can be generalized to other birth cohorts. Note, however, that cohort-related questions of internal validity also become relevant for the interpretation of longitudinal age changes if these estimated age changes are based on cohort-heterogeneous longitudinal samples such as BASE. In other words, in the present study, cohort differences may have not only affected the crosssectional age comparisons but also the overall longitudinal age gradients as estimated for a 30-year period by the latent growth analyses. Concerning the direction of cohort effects, it has typically been suggested that differences in life-history and social conditions such as educational level lead to higher cognitive performance in later birth cohorts and that this, in turn, may exacerbate age differences (e.g., Flynn, 1987; Schaie, 1996; Zelinski \& Burnight, 1997). In studies focusing on old and very old age, however, a second type of cohort effect becomes relevant, and this effect may operate in the opposite direction. Life expectancy is rapidly increasing in industrialized countries, with the consequence that the future oldest old will represent a larger and less positively selected segment of their birth cohort than the present cohort of the oldest old. In contrast to cohort-related education effects, this cohort-related longevity effect is favoring earlier birth cohorts. If both cohort effects are operating, and both are similar in size, they could cancel each other out. While the present design does not allow for a test of this hypothesis, the age-associated 
positive selectivity effects point to the significance of considering such multidirectional and opposing sources of cohort effects.

\section{References}

Albert, M. S., Jones, K., Savage, C. R., Berkman, L., Seeman, T., Blazer, D., \& Rowe, J. C. (1995). Predictors of cognitive change in older persons: MacArthur studies of successful aging. Psychology and Aging, 10, 578-589.

Anstey, K., \& Christensen, H. (2000). Education, activity, health, blood pressure and apolipoprotein $\mathrm{E}$ as predictors of cognitive change in old age: A review. Gerontology, 46, 163-177.

Anstey, K. J., Luszcz, M. A, Giles, L. C., \& Andrews, G. R. (2001). Demographic, health, cognitive, and sensory variables as predictors of mortality in very old adults. Psychology and Aging, 16, 3-11.

Anstey, K. J., Luszcz, M. A., \& Sanchez, L. (2001). Two-year decline in vision but not hearing is associated with memory decline in very old adults in a population-based sample. Gerontology, 47, 289-293.

Arbuckle, J. L. (1996). Full information estimation in the presence of incomplete data. In G. A. Marcoulides \& R. E. Schumacker (Eds.), Advanced structural equation modeling: Issues and techniques (pp. 243-277). Hillsdale, NJ: Erlbaum.

Bäckman, L., Small, B. J., Wahlin, A., \& Larsson, M. (2000). Cognitive functioning in very old age. In F. I. M. Craik \& T. A. Salthouse (Eds.), The handbook of aging and cognition (2nd ed., pp. 499-558). Hillsdale, NJ: Erlbaum.

Baltes, M. M. (1998). The psychiatry of the oldest-old: The fourth age. Current Opinion in Psychology, 11, 411-415.

Baltes, M. M., \& Lang, F. R. (1997). Everyday functioning and successful aging: The impact of resources. Psychology and Aging, 12, 433-443.

Baltes, P. B. (1987). Theoretical propositions of lifespan developmental psychology: On the dynamics between growth and decline. Developmental Psychology, 23, 611-626.

Baltes, P. B. (1997). On the incomplete architecture of human ontogenesis: Selection, optimization, and compensation as foundation of developmental theory. American Psychologist, 52, 366-380.

Baltes, P. B. (2001, September). On the biocultural dynamics of the life course: A difficult journey into the fourth age? First Matilda Riley Lecture. Washington, DC: National Institute on Aging.

Baltes, P. B., \& Mayer, K. U. (Eds.). (1999). The Berlin Aging Study: Aging from 70 to 100. Cambridge, England: Cambridge University Press.

Baltes, P. B., Reese, H. W., \& Nesselroade, J. R. (1977). Lifespan developmental psychology: An introduction to research methods. Monterey, CA: Brooks/Cole.

Baltes, P. B., Schaie, K. W., \& Nardi, A. H. (1971). Age and experimental mortality in a seven-year longitudinal study of cognitive behavior. Developmental Psychology, 5, 18-26.

Baltes, P. B., \& Singer, T. (2001). Plasticity and the ageing mind: An exemplar of the bio-cultural orchestration of brain and behaviour. European Review, 9, 59-76.

Baltes, P. B., \& Smith, J. (1997). A systemic-wholistic view of psychological functioning in very old age: Introduction to a collection of articles from the Berlin Aging Study. Psychology and Aging, 12, 395409

Baltes, P. B., Staudinger, U. M., \& Lindenberger, U. (1999). Life span psychology: Theory and application to intellectual functioning. Annual Review of Psychology, 50, 471-507.

Bell, R. Q. (1953). Convergence: An accelerated longitudinal approach. Child Development, 24, 145-152.

Bell, R. Q. (1954). An experimental test of the accelerated longitudinal approach. Child Development, 381-386.

Berg, C. A. (1996). Practical intelligence and problem solving: Searching for perspectives. In F. Blanchard-Fields \& T. M. Hess (Eds.), Perspectives on cognitive change in adulthood and aging (pp. 323-357). New York: McGraw-Hill.
Bryk, A. S., \& Raudenbush, S. W. (1987). Application of hierarchical linear models to assessing change. Psychological Bulletin, 101, 147158 .

Butler, S. M., Ashford, J. W., \& Snowdon, D. A. (1996). Age, education, and changes in the Mini-Mental State Exam scores of older women: Findings from the Nun Study. Journal of the American Geriatric Society, 44, 675-681.

Carmelli, D., Swan, G. E., LaRue, A., \& Eslinger, P. J. (1997). Correlates of change in cognitive function in survivors from the western Collaborative Group Study. Neuroepidemiology, 16, 285-295.

Cattell, R. B. (1971). Abilities: Their structure, growth, and action. Boston: Houghton Mifflin

Cohen, J. (1977). Statistical power analysis for the behavioral sciences (Rev. ed.). New York: Academic Press.

Colsher, P. L., \& Wallace, R. B. (1991). Longitudinal application of cognitive function measures in a defined population of communitydwelling elders. Annals of Epidemiology, 1, 215-230.

Deary, I. J., MacLennan, W. J., \& Starr, J. M. (1998). Is age kinder to the initially more able?: Differential ageing of a verbal ability in the Healthy Old People in Edinburgh Study. Intelligence, 26, 357-375.

Flynn, J. R. (1987). Massive IQ gains in 14 nations: What IQ tests really measure. Psychological Bulletin, 101, 171-191.

Ghisletta, P., \& Lindenberger, U. (2003). Age-based structural dynamics between perceptual speed and knowledge in the Berlin Aging Study: Direct evidence for ability dedifferentiation with age. Manuscript submitted for publication.

Ghisletta, P., \& McArdle, J. J. (2001). Latent growth curve analyses of the development of height. Structural Equation Modeling, 8, 531-555.

Giambra, L. M., Arenberg, D., Zonderman, A. B., Kawas, C., \& Costa, P. T., Jr. (1995). Adult life span changes in immediate visual memory and verbal intelligence. Psychology and Aging, 10, 123-139.

Gribbin, K., Schaie, K. W., \& Parham, I. A. (1989). Complexity of life style and maintenance of intellectual abilities. Journal of Social Issues, 36, 47-61.

Herlitz, A., Nilsson, L.-G., \& Bäckman, L. (1997). Gender differences in episodic memory. Memory \& Cognition, 25, 801-811.

Hill, R. D., Wahlin, A., Winblad, B., \& Bäckman, L. (1995). The role of demographic and life style variables in utilizing cognitive support for episodic remembering among very old adults. Journal of Gerontology: Psychological Sciences, 50, 219-227.

Horn, J. L. (1982). The theory of fluid and crystallized intelligence in relation to concepts of cognitive psychology and aging in adulthood. In F. I. M. Craik \& G. E. Trehub (Eds.), Aging and cognitive processes: Advances in the study of communication and affect (Vol. 8, pp. 237278). New York: Plenum Press.

Hultsch, D. F., Hertzog, C., Dixon, R. A., \& Small, B. J. (1998). Memory change in the aged. Cambridge, England: Cambridge University Press.

Inouye, S. K., Albert, M. S., Mohs, R., Sun, K., \& Berkman, L. (1993). Cognitive performance in a high-functioning community-dwelling elderly population. Journal of Gerontology: Medical Sciences, 48, M146M151.

Kohn, M. L., \& Schooler, C. (1978). The reciprocal effects of the substantive complexity of work and intellectual flexibility: A longitudinal assessment. American Journal of Sociology, 84, 24-52.

Kohn, M. L., \& Schooler, C. (1983). Work and personality. Norwood, NJ: Ablex.

Laslett, P. (1991). A fresh map of life: The emergence of the Third Age. Cambridge, MA: Harvard University Press.

Lindenberger, U. (2001). Lifespan theories of cognitive development. In N. J. Smelser \& P. B. Baltes (Eds.), International encyclopedia of the social and behavioral sciences (pp. 8848-8854). Oxford, England: Elsevier.

Lindenberger, U., \& Baltes, P. B. (1994). Sensory functioning and intelligence in old age: A strong connection. Psychology and Aging, 9, $339-355$. 
Lindenberger, U., \& Baltes, P. B. (1997). Intellectual functioning in old and very old age: Cross-sectional results from the Berlin Aging Study. Psychology and Aging, 12, 410-432.

Lindenberger, U., \& Ghisletta, P. (in press). Modeling longitudinal changes in old age: From covariance structures to dynamic systems. In R. A. Dixon, L. Bäckman, \& L.-G. Nilsson (Eds.), New frontiers in cognitive aging. New York: Oxford University Press.

Lindenberger, U., Gilberg, R., Little, T. D., Nuthmann, R., Pötter, U., \& Baltes, P. B. (1999). Sample selectivity and generalizability of the results of the Berlin Aging Study. In P. B. Baltes \& K. U. Mayer (Eds.), The Berlin Aging Study: Aging from 70 to 100 (pp. 56-52). Cambridge, England: Cambridge University Press.

Lindenberger, U., Mayr, U., \& Kliegl, R. (1993). Speed and intelligence in old age. Psychology and Aging, 8, 207-220.

Lindenberger, U., \& Reischies, F. M. (1999). Limits and potentials of intellectual functioning in old age. In P. B. Baltes \& K. U. Mayer (Eds.), The Berlin Aging Study: Aging from 70 to 100 (pp. 329-359). Cambridge, England: Cambridge University Press.

Lindenberger, U., Singer, T., \& Baltes, P. (2002). Longitudinal selectivity in aging populations: Separating mortality-associated versus experimental components in the Berlin Aging Study (BASE). Journals of Gerontology. Series B, Psychological Sciences and Social Sciences, 57, P474$\mathrm{P} 482$.

Manton, K. G., \& Vaupel, J. W. (1995). Survival after the age of 80 in the United States, Sweden, France, England, and Japan. New England Journal of Medicine, 333, 1232-1235.

Mayr, U., \& Kliegl, R. (2000). Complex semantic processing in old age: Does it stay or does it go? Psychology and Aging, 15, 29-43.

McArdle, J. J. (1986). Latent growth within behavior genetic models. Behavior Genetics, 16, 163-200.

McArdle, J. J. (1994). Structural factor analysis experiments with incomplete data. Multivariate Behavioral Research, 29, 409-454.

McArdle, J. J., \& Epstein, D. B. (1987). Latent growth curves within developmental structural equation models. Child Development, 58, 110133.

McArdle, J. J., Hamagami, F., Elias, M. F., \& Robbins, M. A. (1991). Structural modeling of mixed longitudinal and cross-sectional data. Experimental Aging Research, 17, 29-52.

Neugarten, B. L. (1974). Age groups in American society and the rise of the young-old. Annals of the American Academy of Political and Social Science (Sept.), 187-198.

Rasbash, J., Browne, W., Goldstein, H., Yang, M., Plewis, I., Healy, M., et al. (2000). A user's guide to mlwin. London: Institute of Education.

Riegel, K. F., \& Riegel, R. M. (1972). Development, drop, and death. Developmental Psychology, 6, 306-319.

Rybash, J. M., Hoyer, W. J., \& Roodin, P. A. (1986). Adult cognition and aging: Developmental changes in processing, knowing, and thinking. New York: Pergamon.
Salthouse, T. A. (1993). Speed and knowledge as determinants of adult age differences in verbal tasks. Journals of Gerontology, 48, P29-P36.

Schaie, K. W. (1965). A general model for the study of developmental problems. Psychological Bulletin, 64, 92-107.

Schaie, K. W. (1996). Intellectual development in adulthood: The Seattle Longitudinal Study. Cambridge, England: Cambridge University Press.

Schaie, K. W., \& Baltes, P. B. (1975). On sequential strategies in developmental research: Description or explanation? Human Development, 18, 384-390.

Schaie, K. W., \& Hofer, S. M. (2001). Longitudinal studies in aging research. In J. E. Birren \& K. W. Schaie (Eds.), Handbook of the psychology of aging (pp. 53-77). San Diego, CA: Academic Press.

Schaie, K. W., Labouvie, G. V., \& Barrett, T. J. (1973). Selective attrition effects in a fourteen-year study of adult intelligence. Journal of Gerontology, 28, 328-334.

Siegler, I. C. (1983). Psychological aspects of the Duke Longitudinal Studies. In K. W. Schaie (Ed.), Longitudinal aspects of adult psychological development (pp. 136-190). New York: Guilford Press.

Siegler, I. C., \& Botwinick, J. (1979). A long-term longitudinal study of intellectual ability of older adults: The matter of selective subject attrition. Journal of Gerontology, 34, 242-245.

Singer, T., Lindenberger, U., \& Baltes, P. B. (2003). Plasticity of memory for new learning in very old age: A story of major loss? Psychology and Aging, 18, 306-317.

Sliwinski, M., \& Buschke, H. (1999). Cross-sectional and longitudinal relationships among age, cognition, and processing speed. Psychology and Aging, 14, 18-33.

Sliwinski, M., Lipton, R. B., Buschke, H., \& Stewart, W. (1996). The effects of preclinical dementia on estimates of normal cognitive functioning in aging. Journals of Gerontology: Psychological Sciences, 51B, 217-225.

Smith, J., \& Baltes, P. B. (1999). Life-span perspectives on development. In M. H. Bornstein \& M. E. Lamb (Eds.), Developmental psycholoogy: An advanced textbook (pp. 47-72). Hillsdale, NJ: Erlbaum.

Suzman, R. M., Willis, D. P., \& Manton, K. G. (Eds.). (1992). The oldest old. New York: Oxford University Press.

Vaupel, J. W., Carey, J. R., Christensen, K., Johnson, T. E., Yashin, A. I., Holm, N. V., et al. (1998). Biodemographic trajectories of longevity. Science, 280, 855-860.

Zelinski, E. M., \& Burnight, K. P. (1997). Sixteen-year longitudinal and time lag changes in memory and cognition in older adults. Psychology and Aging, 12, 503-513.

Zelinski, E. M., Gilewski, M. J., \& Schaie, K. W. (1993). Individual differences in cross-sectional and 3-year longitudinal memory performance across the adult life span. Psychology and Aging, 8, 176-186.

Received June 13, 2001

Revision received September 25, 2001

Accepted October 2, 2002 